\title{
Mechanochemical Conversion of Nano Potassium Hydrogen Terephthalate to Thallium Analogue Nanoblocks with Strong Hydrogen Bonding and Straight Chain Metalophillic Interactions
}

\author{
Elham Mirzadeh $^{[\mathrm{a}]}$, Kamran Akhbari ${ }^{[\mathrm{a}] *}$, Jonathan White $\mathrm{K}^{[\mathrm{b}]}$ \\ ${ }^{a}$ School of Chemistry, College of Science, University of Tehran, P.O. Box 14155-6455, \\ Tehran, Islamic Republic of Iran. \\ Tel.: +98 21 61113734; fax: +98 21 66495291. E-mail address: \\ akhbari.k@khayam.ut.ac.ir (K. Akhbari) \\ ${ }^{\mathrm{b}}$ School of Chemistry and Bio21 Institute, The University of Melbourne, VIC 3010, \\ Australia
}

\begin{abstract}
Irreversible mechanochemical conversion of three-dimensional $\mathrm{K}^{\mathrm{I}}$ coordination polymer $\left[\mathrm{K}\left(\mu_{6}-\mathrm{HTA}\right)\right]_{\mathrm{n}}(\mathbf{1}),\left[\mathrm{H}_{2} \mathrm{TA}=\right.$ terephetalic acid $]$, prepared by sonochemical procedure, to $\mathrm{Tl}^{\mathrm{I}}$ analogue coordination polymer nanoblocks was studied. The structure of $\left[\mathrm{Tl}\left(\mu_{3^{-}}\right.\right.$ HTA) $]_{\mathrm{n}}(\mathbf{2})$ is exactly the same as $\mathbf{1}$ and the Tl ion has distorted octahedral coordination. The carbonyl oxygen is coordinated to two different metal ions, while another oxygen atom is bonded to one metal and participates in a very strong hydrogen bond. Both compounds have secondary straight chain metallophilic interactions. In addition to the same structures of $\mathbf{1}$ and $\mathbf{2}$, the same crystal data of them also approved that the chemistry of thallium(I) parallels that of the potassium(I) in many ways.
\end{abstract}

Keywords: Thallium(I); Coordination Polymer; Hydrogen Bonding; Thallophillic; Nano.

\section{Introduction}

This is the author manuscript accepted for publication and has undergone full peer review but has not been through the copyediting, typesetting, pagination and proofreading process, which may lead to differences between this version and the Version of Record. Please cite this article as doi: $10.1002 /$ aoc.4313

This article is protected by copyright. All rights reserved. 
Extensive research has been devoted to the study of coordination polymers because of the variety of architectures and topologies ${ }^{1}$ and potential applications in ion-exchange ${ }^{2,3}$, sorption $^{4}$, luminescence ${ }^{5}$, magnetism ${ }^{6}$, catalysis ${ }^{7}$, synthesis of nanomaterials ${ }^{8}$ and gas storage ${ }^{9}$. Compared with other materials with mononuclear nature, coordination polymers have particular structures, properties, and reactivities. It is possible to improve physical and chemical properties of CPs, by adjusting the nature and interactions among the individual components ${ }^{10}$. The design of crystalline architectures employing an understanding of the intermolecular interactions available to molecular subunits is the basis for crystal engineering, a key field straddling solid-state molecular assembly and structural analysis, whose importance lies in its capability for allowing control of crystal properties and functions as well as its structure ${ }^{11}$. Much progress has been made using simple systems composed of covalent or strong hydrogen bond coordination compounds with peripheral hydrogen bonding substituents have been used to assemble infinite frameworks of one, two, and three dimensions ${ }^{12,13}$. The new types of hydrogen bonds (HB) in organometallic chemistry can be divided into three types according to the site of coordination and the role of the organometallic species in a hydrogen bonded pair ${ }^{14}$. For one and two dimensional coordination polymers, weak interactions such as hydrogen bonds, electrostatic and Vander Waals interactions play important roles in stabilizing the assembled structures. Hydrogen bonds range from the very strong, comparable with covalent bonds, to the very weak, comparable with Vander Waals forces. Most hydrogen bonds are weak attractions with a binding strength about one-tenth of that of a normal covalent bond ${ }^{15,16}$. Mechanochemical synthesis, reactions conducted by grinding solid reactants together with no or minimal solvent, has been demonstrated as an excellent technique for the formation of both organic and inorganic compounds ${ }^{17,18}$. Mechanochemistry is viewed as an alternative approach to chemical synthesis and is not always considered when developing manufacturing processes of fine chemicals ${ }^{19}$. Coordination compounds with peripheral hydrogen bonding substituents can present 
synthetic challenges to supramolecular chemists who are interested in hydrogen-bonded assembly, since the metal ions may themselves coordinate with the electronegative atoms that are sources of strong hydrogen bond donors and acceptors ${ }^{20}$. In addition, the counterions that often escort metal complexes can serve as hydrogen bond donors or acceptors. Our aim was to focus on reversible/nonreversible structural transformations in thallium(I) coordination polymers by solid-state cation exchange process. Specially thallium(I) compounds are similar in structure and chemical properties to potassium which makes it easy for us to study their structural transformations in solid-state. This in this work we would like to study mechanochemical conversion of nano-structured $\left[\mathrm{K}\left(\mu_{6}-\mathrm{HTA}\right)\right]_{\mathrm{n}}(\mathbf{1})$ coordination polymer ${ }^{21}$, synthesized with sonochemical reaction, to $\left[\mathrm{Tl}\left(\mu_{3}-\mathrm{HTA}\right)\right]_{\mathrm{n}}(\mathbf{2})$, $\left(\mathrm{H}_{2} \mathrm{TA}=\right.$ terephtalic acid $)$, also the reversibility of this solid-state conversion was studied. It is good to know that particle size and morphology of nanostructures depend on their synthesis method. For example, extensive research on synthesis of iron vanadate is being conducted using different techniques such as sol-gel ${ }^{22}$, wet chemical ${ }^{23}$, microwave ${ }^{24}$, hydrothermal $^{25}$, solid-state ${ }^{26}$ and precipitation ${ }^{27-29}$. Among several different synthetic paths, many kinds of CPs have been prepared by sonochemical method ${ }^{30}$. During ultrasonic process water gets pyrolyzed into $\mathrm{OH}$ and $\mathrm{H}$ radicals. Both radicals are very active and play important role in sonochemical reaction. ${ }^{24}$ Ultrasonic irradiation is considered as a green energy source because of shorter reaction times and higher yields in comparison with thermal energy sources. ${ }^{30}$

\section{Experimental}

\section{Materials and Physical Techniques.}

All reagents and solvents for the synthesis and analysis were commercially available and were used as received. The molecular structure plots were prepared using Mercury software $^{31}$. PARSONIC $15 \mathrm{~S}$ ultrasonic bath (with the frequency $28 \mathrm{KHz}$ ) was used for the ultrasonic irradiation. Melting points were measured on an Electrothermal 9100 
apparatus and are uncorrected. IR spectra were recorded using an Equinox 55 FT-IR spectrometer (Bruker, Bremen, Germany) in ATR form, in the range of $400-4000 \mathrm{~cm}^{-1}$ with $4.0 \mathrm{~cm}^{-1}$ resolution and the 16 scan's numbers. Intensity data for $\left[\mathrm{Tl}\left(\mu_{3}-\mathrm{HTA}\right)\right]_{\mathrm{n}}(2)$ was collected with an Oxford Diffraction SuperNova CCD diffractometer using Mo-K $\mathrm{K}_{\alpha}$ radiation, the temperature during all data collections was maintained at 130.0(1) K using an Oxford Cryosystems cooling device. The structures were solved by direct methods and difference Fourier synthesis ${ }^{32}$. Thermal ellipsoid plots were generated using the program ORTEP- $3^{33}$ within the WINGX suite of programs ${ }^{34}$. X-ray powder diffraction (XRD) measurements were performed using an X' Pert MPD diffractometer manufactured by Philips with monochromatized $\mathrm{Cuk}_{\alpha}$ radiation with scan rate of 0.02 degree per sec and simulated XRD powder patterns based on single crystal data were prepared using the Mercury software. The samples were characterized with a scanning electron microscope (Philips XL 30) with gold coating.

\section{Synthesis of $\left[\mathrm{K}\left(\mu_{6}-\mathrm{HTA}\right)\right]_{\mathrm{n}}$ (1) nanostructures by a sonochemical process}

To prepare nano-sized $\left[\mathrm{K}\left(\mu_{6}-\mathrm{HTA}\right)\right]_{\mathrm{n}}(\mathbf{1}), 5 \mathrm{mmol}(0.831 \mathrm{~g})$ of the terephthalic $\operatorname{acid}\left(\mathrm{H}_{2} \mathrm{TA}\right)$ was dissolved in $15 \mathrm{ml}$ methanol (A $0.33 \mathrm{M}$ solution) and was mixed and stirred with solution of $5 \mathrm{mmol}(0.280 \mathrm{~g}) \mathrm{KOH}$ in $5 \mathrm{ml} \mathrm{H}_{2} \mathrm{O}\left(\mathrm{A} 1.0 \mathrm{M}\right.$ solution) at $100{ }^{\circ} \mathrm{C}$ for about 45 minutes and then this mixture was positioned in an ultrasonic bath. After 4 hours white precipitate was obtained which was filtered and dried at room temperature. d.p. $=$ above $300{ }^{\circ} \mathrm{C}$, yield: $0.791 \mathrm{~g}, 77.5 \%$ based on final product.

\section{Mechanochemical reaction of 1 with $\mathrm{TINO}_{3}$ in order to synthesis of $\left[\mathrm{Tl}\left(\mu_{3}-\mathrm{HTA}\right)\right]_{\mathrm{n}}$} (2).

This reaction was performed between $3.5 \mathrm{mmol}(0.715 \mathrm{~g})$ of $\left[\mathrm{K}\left(\mu_{6}-\mathrm{HTA}\right)\right]_{\mathrm{n}}(\mathbf{1})$ with 4.5 mmol $(1.199 \mathrm{~g})$ of $\mathrm{TlNO}_{3}$. These two reactants were mixed in mortar and ground up for 30 minutes through liquid-assisted grinding (LAG) method by adding a few droplets of 
water. Then the mixture was four times washed with distilled water until the unreacted $\mathrm{TINO}_{3}$ and produced $\mathrm{KNO}_{3}$ removed from it and the pure product was separated. d.p. $=$ above $300{ }^{\circ} \mathrm{C}$, yield: $1.091 \mathrm{~g}, 84.4 \%$ based on final product.

\section{Checking the reversibility of this solid state structural transformation with $\mathrm{KNO}_{3}$}

This reaction was performed between $1 \mathrm{mmol}(0.369 \mathrm{~g})$ of 2 with $1.5 \mathrm{mmol}(0.150 \mathrm{~g})$ of $\mathrm{KNO}_{3}$. These two reactants were mixed in mortar and ground up for 30 minutes through liquid-assisted grinding (LAG) method by adding a few droplets of water. The XRD pattern of resulting precipitate approved that this transformation is irreversible (Figure 1f in the SI) and in $\left[\mathrm{Tl}\left(\mu_{3}-\mathrm{HTA}\right)\right]_{\mathrm{n}}(2)$ was not converted back to 1 upon solid-state reaction with $\mathrm{KNO}_{3}$. Then the mixture was four times washed with distilled water until the unreacted $\mathrm{KNO}_{3}$ removed from it and the pure phase of $\mathbf{2}$ was separated. d.p. = above 300 ${ }^{\circ} \mathrm{C}$.

\section{Synthesis of $\left[\mathrm{Tl}\left(\mu_{3}-\mathrm{HTA}\right)\right]_{\mathbf{n}}(2)$ and preparation of its single crystals.}

$1 \mathrm{mmol}(0.166 \mathrm{~g})$ of the terephthalic $\operatorname{acid}\left(\mathrm{H}_{2} \mathrm{TA}\right)$ was dissolved in $20 \mathrm{ml}$ methanol (A $0.05 \mathrm{M}$ solution) and was mixed and stirred with solution of $2 \mathrm{mmol}(0.114 \mathrm{~g}) \mathrm{KOH}$ in 5 $\mathrm{ml} \mathrm{H}_{2} \mathrm{O}$ (A $0.4 \mathrm{M}$ solution) at $100{ }^{\circ} \mathrm{C}$ for about 45 minutes, then a solution of $2 \mathrm{mmol}$ $(0.532 \mathrm{~g}) \mathrm{TlNO}_{3}$ in $5 \mathrm{ml} \mathrm{H} \mathrm{H}_{2} \mathrm{O}$ (A $0.4 \mathrm{M}$ solution) was added to the mixture and the heating and stirring process was continued for about one hour. After filtering it was allowed to evaporate for several days and then suitable crystals were obtained. The crystals was separated and kept in its mother liquid. d.p. = above $300{ }^{\circ} \mathrm{C}$, yield: $0.202 \mathrm{~g}$, $54.7 \%$ based on final product.

\section{Results and discussion}

This article is protected by copyright. All rights reserved. 
The reaction between terephthalic $\operatorname{acid}\left(\mathrm{H}_{2} \mathrm{TA}\right)$ and $\mathrm{KOH}$ in ultrasonic bath resulted in formation of white powder which was dried at room temperature. A comparison between the XRD patterns simulated from single crystal X-ray data of potassium hydrogen terephthalate $^{21}$ (Figure 1a) and that of the prepared powder (Figure 1b), approved the formation of $\left[\mathrm{K}\left(\mu_{6}-\mathrm{HTA}\right)\right]_{\mathrm{n}}$ (1) (Figures S1 in the SI and 2). HTA is bridging between six $\mathrm{K}$ ions and can be considered as hexadentate ligand (Figure S1a in the SI). J. A. Kaduk reported that in $\mathbf{1}$, the $\mathrm{K}$ ion has distorted octahedral coordination (Figure S1a in the SI) ${ }^{21}$. The carbonyl oxygen $\mathrm{O} 1$ is coordinated to two different $\mathrm{K}$, while $\mathrm{O} 2$ is bonded to one $\mathrm{K}$ and participates in a very strong hydrogen bond $(\mathrm{O} 2 \cdots \mathrm{O} 22.46 \AA$, Figure $\mathrm{S} 1 \mathrm{~b}$ in the SI ${ }^{21}$. There is a center of symmetry midway between the two $\mathrm{O} 2$ in the hydrogen bond $^{21}$. Compound $\mathbf{1}$ is a three-dimensional coordination polymer with lozenge framework along the crystallographic c axis (Figure 2a) and has secondary straight chain $\mathrm{K} \cdots \mathrm{K}$ metallophilic interactions (Table 2) with distance of $3.77 \AA$ which is lower than the sum of the vander Waals radii of two $\mathrm{K}$ atoms ${ }^{35}$ (5.50 $\AA$, Figure $2 b$ ). SEM image of the obtained powder approved that compound $\mathbf{1}$ micro and nanostructures were formed under ultrasonic irradiations (Figure 3a). Since thallium might be regarded as a relativistic alkali metal because $\mathrm{Tl}$ chemistry parallels that of the alkali metals in many ways ${ }^{36}$ and the well-known toxicity of thallium compounds may also be associated with nonreversibility of the complexation reactions as compared to the action of potassium cations $^{37}$, we decided to study the structural changes of $\mathbf{1}$ during conversion of it to Tl(I) complex of $\mathrm{HTA}^{-}$(2) by mechanochemical reaction of 1 with excess $\mathrm{TINO}_{3}$. The XRD pattern of compound $\mathbf{1}$ after solid-state mechanochemical reaction with excess $\mathrm{TlNO}_{3}$ (Figure 1c) approved that ion exchange process of $\mathrm{K}(\mathrm{I})$ with $\mathrm{Tl}(\mathrm{I})$ was occurred. After removal of $\mathrm{KNO}_{3}$ and unreacted $\mathrm{TINO}_{3}$ from the products mixture, the pure phase of 2 (Figure 1d) was separated. SEM image of the mixture obtained from mechanochemical reaction of 1 with excess $\mathrm{TINO}_{3}$ indicated the formation of nanostructures (Figure $3 \mathrm{~b}$ ) with different morphology to $\mathbf{1}$ (Figure 3a). After washing the prepared mixture with 
water, pure phase of compound 2 with nanoblock morphology was seen (Figure 3c). A comparison between the XRD patterns simulated from single crystal X-ray data of $\mathrm{Tl}(\mathrm{I})$ complex of $\mathrm{HTA}^{-}$(2) (Figure 1e) and that of the prepared nanoblocks (Figure 1d), approved that the nanoblocks have the same structure as $\mathbf{2}$. It should be noted that some differences between the peak intensity of simulated and experimental patterns is depending on textural features such as preferred orientations of nanocrystaline samples. Thus our attempts for synthesis of $\mathbf{2}$ from mechanochemical reaction of $\mathbf{1}$ with exess $\mathrm{TINO}_{3}$ is successful. In order to study the structure of $\mathbf{2}$ in detail, a reaction was done between $\mathrm{H}_{2} \mathrm{TA}$ and $\mathrm{TlNO}_{3}$ which provided crystalline materials of the general formula $\left[\mathrm{Tl}\left(\mu_{3}-\mathrm{HTA}\right)\right]_{\mathrm{n}}(\mathbf{2})$. Figure S2a (In the SI) shows the primary structural building unit of 2. The structure of $\mathbf{2}$ is exactly the same as $\mathbf{1}$ and the $\mathrm{Tl}$ ion has distorted octahedral coordination (Figure $\mathrm{S} 2 \mathrm{~b}$ in the SI). The carbonyl oxygen $\mathrm{O} 1$ is coordinated to two different $\mathrm{Tl}$ ions, while $\mathrm{O} 2$ is bonded to one $\mathrm{Tl}$ and participates in a very strong hydrogen

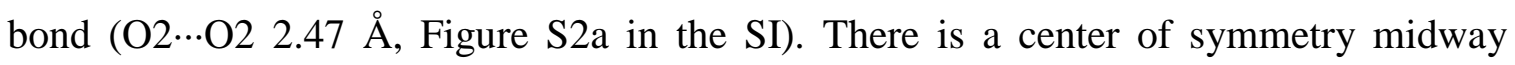
between the two $\mathrm{O} 2$ in the hydrogen bond too. Compound 2 is a three-dimensional coordination polymer with lozenge framework along the crystallographic c axis (Figures

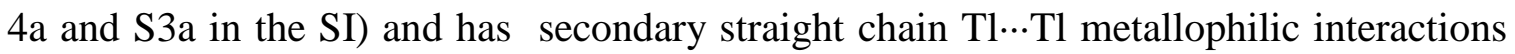
(Table 2) with distance of $3.76 \AA$ which is lower than the sum of the vander Waals radii of two Tl atoms ${ }^{35}$ (4.40 $\AA$, Figures $4 \mathrm{~b}$ and S3b in the SI). Against to those observed in thallium(I) compounds ${ }^{38-47}$, in compound 2 , the lone pair of $\mathrm{Tl}(\mathrm{I})$ is 'inactive' in the solidstate and the arrangement of $\mathrm{O}$-atoms do not suggest a gap or hole in coordination geometry around the $\mathrm{Tl}(\mathrm{I})$ coordination sphere (Figure S2b in the SI). Our search also shows that $\mathrm{Tl}$ in compound $\mathbf{2}$ does not involve in $\mathrm{Tl} \cdots \mathrm{C}$ and $\mathrm{Tl} \cdots \mathrm{H}$ interactions.

The XRD pattern of 2 after mechanochemical reaction of it with $\mathrm{KNO}_{3}$ (Figure 1f) is exactly the same as those observed in compound 2 (Figure 1d,e). Thus this transformation is irreversible. A comparison between crystal data of these two compounds (Table 1), shows that these two compounds have the same crystal system and 
similar space groups, unit cell dimensions and volume too. Thus in addition to the same structures of $\mathbf{1}$ and $\mathbf{2}$, the same crystal data of them also approved that the chemistry of thallium(I) parallels that of the potassium(I) in many ways. The SEM image of the prepared sample from the reverse reaction indicates the existence of compound $\mathbf{2}$ nanoblocks (Figure 3d). Thus its morphology does not change after grinding of it with excess $\mathrm{KNO}_{3}$. It should be also noted that compound $\mathbf{2}$ is a $3 \mathrm{D}$ coordination polymer (Figure 4) and its tendency to form 3D nanostructures like nanoblocks (Figure S2b-e in the SI), in addition to other factors, may be attributed to its crystal structure too. A comparison between the coordination geometry of the $\mathrm{K}$ and $\mathrm{Tl}$ atoms in the coordination polymers of 1 and $\mathbf{2}$ shows that during this solid-state cation exchange process, no structural changes in coordination mode of $\mathrm{HTA}^{-}$and coordination sphere of $\mathrm{K}^{+}$and $\mathrm{Tl}^{+}$ ions were occurred.

To further confirm of this irreversible solid-state reaction, IR spectra were recorded for all of five samples prepared during these conversion (Figure S4 in the SI). The IR spectrum of prepared powder of $\mathbf{1}$ under ultrasonic irradiation (Figure S4a in the SI) shows characteristic absorption bands for the HTA ligand. The absorption bands with variable intensity in the frequency range $1200-1500 \mathrm{~cm}^{-1}$ correspond to ring vibrations of the aromatic rings in HTA ligand. A comparison between the IR spectrum of compound 1 synthesized by sonochemical process (Figure S4a in the SI), compound 1 after solidstate mechanochemical reaction with excess $\mathrm{TINO}_{3}$ (Figure $\mathrm{S} 4 \mathrm{~b}$ in the $\mathrm{SI}$ ), compound 2 after removal of $\mathrm{KNO}_{3}$ and unreacted $\mathrm{TlNO}_{3}$ from the products mixture (Figure $\mathrm{S} 4 \mathrm{c}$ in the SI), IR spectrum of 2 after liquid-assisted mechanochemical reaction with $\mathrm{KNO}_{3}$ (Figure S4d in the SI) and IR spectrum of the sample after removal of unreacted $\mathrm{KNO}_{3}$ from the products mixture (Figure S4e in the SI) are exactly similar to each other which is due to the exactly the same structures of $\mathbf{1}$ and $\mathbf{2}$. In none of each IR spectra, no weak broad band around 2800-3500 $\mathrm{cm}^{-1}$ was observed which indicated the existence of very strong hydrogen bonding interaction in $\mathbf{1}$ and $\mathbf{2}$ similar to the covalent $\mathrm{O}-\mathrm{H}$ bonds. 
TGA data (Figure 5a) indicated that $\mathbf{1}$ is stable up to $550{ }^{\circ} \mathrm{C}$ and did not show any mass loss up to this temperature. The thermal behavior of compound $\mathbf{1}$ after solid-state mechanochemical reaction with excess $\mathrm{TlNO}_{3}$ (Figure 5b) is different from 1 (Figure 5a) which approved formation of other new compound (2) from this conversion. This TG curve shows that this sample is stable up to $365{ }^{\circ} \mathrm{C}$. It seems that the observed mass loss of $21.8 \%$ (calcd $23.8 \%$ for pure phase of 2 ) which accompanied with an exothermic peak at $398{ }^{\circ} \mathrm{C}$ may be attributed to removal of two $\mathrm{CO}_{2}$ molecules from $\mathrm{HTA}^{-}$of $\mathbf{2}$. Figure $5 \mathrm{c}$ indicated that pure phase of $\mathbf{2}$ is stable up to $475^{\circ} \mathrm{C}$ and the observed mass loss of $21.7 \%$ (calcd 23.8\%) which accompanied with an endothermic peak at $525^{\circ} \mathrm{C}$ may be attributed to removal of two $\mathrm{CO}_{2}$ molecules from $\mathrm{HTA}^{-}$ligand of $\mathbf{2}$. A comparison between Figures $5 \mathrm{~b}$,c shows that impurity (like inorganic salts) can affect on thermal stability of our product. Here existence of unreacted $\mathrm{TlNO}_{3}$ and produced $\mathrm{KNO}_{3}$ decreases the thermal stability of $\mathbf{2}$ up to about $110{ }^{\circ} \mathrm{C}$. Thermal behavior of compound $\mathbf{2}$ after mechanochemical reaction of it with excess $\mathrm{KNO}_{3}$ was also examined (Figure 5d). The result is exactly the same as that obtained from mechanochemical reaction of 1 with excess $\mathrm{TlNO}_{3}$ (Figure 5b). This observation also indicates that conversion of $\mathbf{1}$ to $\mathbf{2}$ is irreversible and in this stage we only have mixture of $\mathbf{2}$ and $\mathrm{KNO}_{3}$. Finally thermal behavior of compound 2 pure phase obtained after washing the mixture from previous stage was studied (Figure 5e). Its TG curve indicated that pure phase of 2 which obtained after mechanochemical treatment with $\mathrm{KNO}_{3}$ is stable up to $355{ }^{\circ} \mathrm{C}$. After this temperature, it showed two steps with observed mass losses of 7.1\% (between 355-400 ${ }^{\circ} \mathrm{C}$ with an exothermic effect at $385{ }^{\circ} \mathrm{C}$ ) and $11.2 \%$ (between $495-547{ }^{\circ} \mathrm{C}$ ). Although the XRD pattern of this sample (Figure 1g) is exactly the same as $\mathbf{2}$ obtained from mechanochemical reaction of $\mathbf{1}$ with $\mathrm{TINO}_{3}$ (Figure 1d) and the XRD pattern simulated from single crystal X-ray data of $\mathbf{2}$ (Figure 1e), its thermal behavior (Figure 5e) showed some differences from pure phase of $\mathbf{2}$ synthesized from mechanochemical reaction of $\mathbf{1}$ 
with $\mathrm{TINO}_{3}$ (Figure 5c). Probably mechanochemical grinding of $\mathbf{2}$ at final step affects on thermal stability of it.

\section{Conclusions}

In summary, irreversible solid-state structural conversion of three-dimensional $\mathrm{K}^{\mathrm{I}}$ coordination polymer $\left[\mathrm{K}\left(\mu_{6}-\mathrm{HTA}\right)\right]_{\mathrm{n}}$ (1) synthesized by sonochemical procedure, to $\mathrm{Tl}^{\mathrm{I}}$ analogue coordination polymer nanoblocks has been observed upon mechanochemical reaction of compound 1 with $\mathrm{TlNO}_{3}$. This irreversible exchange is similar to that occurred in biological systems approved the toxicity of thallium. The structure of $\left[\operatorname{Tl}\left(\mu_{3^{-}}\right.\right.$ $\mathrm{HTA})]_{\mathrm{n}}(\mathbf{2})$ is exactly the same as $\mathbf{1}$ and the $\mathrm{Tl}$ ion has distorted octahedral coordination. The carbonyl oxygen is coordinated to two different metal ions, while another oxygen atom is bonded to one metal and participates in a very strong hydrogen bond. Both compounds have secondary straight chain metallophilic interactions. Against to those observed in thallium(I) compounds, in compound 2, the lone pair of $\mathrm{Tl}(\mathrm{I})$ is 'inactive' in the solid-state and the arrangement of O-atoms do not suggest a gap or hole in coordination geometry around the $\mathrm{Tl}(\mathrm{I})$ coordination sphere. In addition to the same structures of $\mathbf{1}$ and $\mathbf{2}$, the same crystal data of them also approved that the chemistry of thallium(I) parallels that of the potassium(I) in many ways. The IR spectra of them no weak broad band around $2800-3500 \mathrm{~cm}^{-1}$ was observed which indicated the existence of very strong hydrogen bonding interaction in $\mathbf{1}$ and $\mathbf{2}$ similar to the covalent $\mathrm{O}-\mathrm{H}$ bonds. Studying these types of solid-state mechanochemical reaction is being investigated in our laboratory.

\section{Supplementary material.}

Complete bond lengths and angles, co-ordinates and displacement parameters have been deposited at Cambridge Crystallography Data Center. Supplementary data are available 
from the CCDC, 12 Union Road, Cambridge CB2 1EZ, UK on request, quoting the deposition number 1565856 for compound 2.

\section{Acknowledgements}

The authors would like to acknowledge the financial support of University of Tehran for this research under grant number 01/1/389845.

\section{References}

[1] L. Zhou, C. Wang, X. Zheng, Z. Tian, L. Wen, H. Qu, D. Li. Dalton Trans, 2013, 42, $16375-16386$.

[2] H. Nara, Sh. Tsuda, T. Osaka, J. Solid State Electrochem, 2017, 21, 1925-1937.

[3] Y. Noori, K. Akhbari, RSC Adv. 2017, 7, 1782-1808.

[4] Q. Chen, Y. Y. Jia, Z. Chang, T. T. Wang, B. Y. Zhou, R. Feng and X. H. Bu. Pillared, Cryst. Growth Des, 2014, 14, 5189-5195.

[5] M. D. Allendorf, C. A. Bauer, R. K. Bhakta and R. J .T. Houk. Chem. Soc. Rev, 2009, $38,1330-1352$.

[6] S-S. Pedro, P. Brandão, F. N. Shi, J. C. G. Tedesco, and M. S. Reis. Polyhedron, 2014, 81,210-215.

[7] L. T. L. Nguyen, C. V. Nguyen, G. H. Dang, K. K. A. Le, N. T. S. Phan, J. Mol. Catal. A: Chem, 2011, 349, 28-35.

[8] E. Mirzadeh, K. Akhbari, CrystEngComm, 2016, 18, 7410-7424.

[9] Q. Li, C. Tian, H. Zhang, J. Qian and S. Du. CrystEngComm, 2014, 16, 9208-9215.

[10] Y. Chen, X. L. Chen, Y. Chen, L. Jia, M. H. Zeng, Inorg. Chem. Commun. 2017, 84, $182-185$.

[11] F. Z. Bu, X. J. Tan, D. X. Xing, and Ch. Wang. Acta Cryst Sec C: Structural Chemistry, 2017, 73.

This article is protected by copyright. All rights reserved. 
[12] R. A. Agarwal. Inorg. Chem. Commun. 2016, 70, 115-117.

[13] Q. Y. Wang, Y. He, Q. H. Meng, X. L. Zhang, Z. T. Zhang J. Coord. Chem, 2017, 70, 1105-1120.

[14] L. M. Epstein, E. S. Shubina. Coord. Chem. Rev. 2002, 231, 165-181.

[15] A. M, Beatty, Coord. Chem, Rev, 2003, 246, 131-143.

[16] S. Wang, P. Liebing, F. Oehler, J. W. Gilje, C. G. Hrib, F. T. Edelmann, Cryst. Growth Des. 2017, 17, 3402-3410.

[17] G. Das, D. B. Shinde, S. Kandambeth, B. P. Biswal and R. Banerjee. Chem. Comm, 2014, 50, 12615-12618.

[18] D. E. Crawford and J. Casaban. Adv. Mater, 2016, 28, 5747-5754.

[19] A. Nasser, U. Mingelgrin, Appl. Clay Sci, 2012, 67, 141-150.

[20] D. L. Fang, S. Y. Mo, K. F. Wu, Z. J. Huang, Transition Met. Chem, 2017, 42, $273-$ 283.

[21] J. A. Kaduk, Acta Cryst Sect. B. 2000, 56, 474-485.

[22] M. Ghiyasiyan-Arani, M. Salavati-Niasari, M. Masjedi-Arani, F. Mazloom, J. Mater. Sci: Mater Electron. 2018, 29, 474-485

[23] M. Ghiyasiyan-Arani, M. Masjedi-Arani, M. Salavati-Niasari, J. Mater. Sci: Mater Electron. 2016, 27, 4871-4878.

[24] M. Ghiyasiyan-Arani, M. Salavati-Niasari, S. Naseh, Ultrason. Sonochem. 2017, 39, 494-503.

[25] M. Mousavi-Kamazani, M. Salavati-Niasari, M. Goudarzi, Z. Zarghami, J. Mol. Liquids, 2017, 242, 653-661.

[26] M. Ghiyasiyan-Arani, M. Masjedi-Arani, M. salavati-Niasari, J. Mol. Catalysis A: Chemical, 2016, 425, 31-42.

[27] M. Ghiyasiyan-Arani, M. Masjedi-Arani, D. Ghanbari, S. Bagheri, M. SalavatiNiasari, Scientific reports. 2016, 6, 1-9.

This article is protected by copyright. All rights reserved. 
[28] M. Ghiyasiyan-Arani, M. Masjedi-Arani, M. Salavati-Niasari, J. Mol. Liquids. 2016, 216, 59-66.

[29] M. Ghiyasiyan-Arani, M. Masjedi-Arani, M. Salavati-Niasari, J. Nanostruct., 2015, 5, 437-441.

[30] F. Shahangi Shirazi, K. Akhbari, Ultrason. Sonochem. 2016, 31, 51-61.

[31] C. F. Macrae, P. R. Edgington, P. McCabe, E. Pidcock, G. P. Shields, R. Taylor, M. J. Appl. Cryst. 2006, 39, 453-457.

[32] G. M. Sheldrick, Acta Cryst. Sect. C, 2015, 71, 3-8.

[33] L. J. Farrugia, J. Appl. Cryst. 1997, 30, 565-565.

[34] L. J. Farrugia, J. Appl. Cryst. 1999, 32, 837-838.

[35] A. Bondi, J. phys. Chem., 1964, 68, 441-451.

[36] F. Wiesbrock, H. Schmidbaur, J. Inorg. Biochem. 2004, 98, 473-484.

[37] K. Akhbari, A. Morsali, Coord. Chem. Rev. 2010, 254, 1977-2006.

[38] K. Akhbari, A. Morsali, CrystEngComm. 2012, 14, 1618-1628.

[39] K. Akhbari, A. Morsali, Polyhedron., 2011, 30, 1456-1462.

[40] K. Akhbari, A. Morsali, Inorg. Chim. Acta., 2009, 362, 1692-1700.

[41] K. Akhbari, A. Morsali, J. Mol. Struct., 2008, 878, 65-70.

[42] K. Akhbari, A. Morsali, J. Organomet. Chem. 2007, 692, 5109-5112.

[43] K. Akhbari, A. Morsali, J. Organomet. Chem. 2007, 692, 5141-5146.

[44] K. Akhbari, A. Morsali, Inorg. Chem. Commun. 2007, 10, 1189-1193.

[45] K. Akhbari, A. Morsali, Inorg. Chem. Commun. 2007, 10, 178-182.

[46] M. Moeinian, K. Akhbari, J. Boonmak, S. Youngme, Polyhedron, 2016, 118, 6-11.

[47] M. Moeinian, K. Akhbari, S. Kawata, R. Ishikawa, RSC Adv, 2016, 6, 82447-82449.

This article is protected by copyright. All rights reserved. 
Table 1. Crystal data and structure refinement for compounds $\mathbf{1}$ and $\mathbf{2}$.

\begin{tabular}{lll}
\hline Identification code & $\mathbf{2}$ & $\mathbf{1}$ \\
Empirical formula & $\mathrm{C}_{8} \mathrm{H}_{5} \mathrm{O}_{4} \mathrm{Tl}$ & $\mathrm{C}_{8} \mathrm{H}_{5} \mathrm{O}_{4} \mathrm{~K}$ \\
\hline
\end{tabular}




\begin{tabular}{|c|c|c|}
\hline Formula weight & 369.49 & 204.22 \\
\hline Temperature & $130.01 \mathrm{~K}$ & 298 \\
\hline Wavelength & $0.71073 \AA$ & $0.71073 \AA$ \\
\hline Crystal system & Monoclinic & Monoclinic \\
\hline Space group & $\mathrm{C} 2 / \mathrm{c}$ & $\mathrm{C} 2 / \mathrm{c}$ \\
\hline Unit cell dimensions & $\begin{array}{l}\mathrm{a}=18.8490(10) \AA \\
\mathrm{b}=3.7564(2) \AA \\
\mathrm{c}=11.3409(6) \AA \\
\alpha=90.00^{\circ} \\
\beta=96.888(6)^{\circ} \\
\gamma=90.00^{\circ}\end{array}$ & $\begin{array}{l}\mathrm{a}=18.825(4) \AA \\
\mathrm{b}=3.7700(8) \AA \\
\mathrm{c}=11.179(2) \AA \\
\alpha=90.00^{\circ} \\
\beta=94.56(3)^{\circ} \\
\gamma=90.00^{\circ}\end{array}$ \\
\hline Volume & $797.19(7) \AA^{3}$ & $790.9(3) \AA^{3}$ \\
\hline $\mathrm{Z}$ & 4 & 4 \\
\hline Density (calculated) & 3.079 g.cm ${ }^{-3}$ & 1.715 g.cm ${ }^{-3}$ \\
\hline Absorption coefficient & $20.234 \mathrm{~mm}^{-1}$ & 0.645 \\
\hline$F(000)$ & 664 & 416 \\
\hline Crystal size & $0.349 \times 0.324 \times 0.265 \mathrm{~mm}^{3}$ & $0.42 \times 0.1 \times 0.04 \mathrm{~mm}^{3}$ \\
\hline Theta range for data collection & 4.4680 to $35.7190^{\circ}$ & $\ldots$ \\
\hline Index ranges & $\begin{array}{l}-17 \leq h \leq 24 \\
-4 \leq k \leq 4 \\
-14 \leq l \leq 14\end{array}$ & $\begin{array}{l}0 \leq h \leq 18 \\
-3 \leq k \leq 3 \\
-10 \leq l \leq 10\end{array}$ \\
\hline Independent reflections & 884 & 376 \\
\hline Absorption correction & Multi-scan & None \\
\hline Data / restraints / parameters & 918 / 0 / 61 & $367 / 1 / 72$ \\
\hline Goodness-of-fit on $\mathrm{F}^{2}$ & 1.078 & 1.018 \\
\hline Final $R$ indices $[\mathrm{I}>2 \sigma(I)]$ & $\begin{array}{l}\mathrm{R}_{1}=0.0390 \\
\mathrm{wR}_{2}=0.1006\end{array}$ & $\begin{array}{l}\mathrm{R}_{1}=0.0302 \\
\mathrm{wR}_{2}=\ldots\end{array}$ \\
\hline$R$ Indices (all data) & $\mathrm{R}_{1}=0.0401$ & $\mathrm{R}_{1}=0.0455$ \\
\hline & $w_{2}=0.1013$ & $w R_{2}=0.0715$ \\
\hline Ref. & This work & 21 \\
\hline
\end{tabular}

This article is protected by copyright. All rights reserved. 
Table 2. Selected bond lengths /Å and angles $/{ }^{\circ}$ for compounds $\mathbf{1}$ and 2.

\begin{tabular}{llll}
\hline Compound 1 & (This work) & Compound 2 & (Ref. 21) \\
$\mathrm{Tl}(1)-\mathrm{Tl}(1)$ & $3.7564(2)$ & $\mathrm{O}(1)-\mathrm{K}-\mathrm{O}(1)$ & $96.22(13)$ \\
$\mathrm{Tl}(1)-\mathrm{O}(1)$ & $2.786(5)$ & $\mathrm{O}(1)-\mathrm{K}-\mathrm{O}(1)$ & $177.39(11)$ \\
$\mathrm{O}(1)-\mathrm{Tl}(1)-\mathrm{Tl}(1)$ & $129.89(10)$ & $\mathrm{O}(1)-\mathrm{K}-\mathrm{O}(1)$ & $86.39(7)$ \\
$\mathrm{O}(1)-\mathrm{Tl}(1)-\mathrm{O}(1)$ & $100.2(2)$ & $\mathrm{O}(1)-\mathrm{K}-\mathrm{O}(1)$ & $91.00(12)$ \\
$\mathrm{O}(1)-\mathrm{Tl}(1)-\mathrm{Tl}(1)$ & $50.11(10)$ & $\mathrm{O}(1)-\mathrm{K}-\mathrm{O}(2)$ & $98.91(8)$ \\
$\mathrm{Tl}(1)-\mathrm{Tl}(1)-\mathrm{Tl}(1)$ & 180.0 & $\mathrm{O}(1)-\mathrm{K}-\mathrm{O}(2)$ & $112.64(8)$ \\
& & $\mathrm{O}(1)-\mathrm{K}-\mathrm{O}(2)$ & $80.03(8)$ \\
& & $\mathrm{O}(1)-\mathrm{K}-\mathrm{O}(2)$ & $66.82(8)$ \\
& & $\mathrm{O}(1)-\mathrm{K}-\mathrm{O}(2)$ & $112.64(8)$ \\
& & $\mathrm{O}(1)-\mathrm{K}-\mathrm{O}(2)$ & $98.91(8)$ \\
& & $\mathrm{O}(2)-\mathrm{K}-\mathrm{O}(2)$ & $132.31(15)$ \\
& & $\mathrm{O}(1)-\mathrm{K}-\mathrm{K}$ & $48.11(6)$ \\
& & $\mathrm{O}(1)-\mathrm{K}-\mathrm{K}$ & $134.50(6)$ \\
& & $\mathrm{O}(2)-\mathrm{K}-\mathrm{K}$ & $113.84(7)$ \\
& & $\mathrm{O}(1)-\mathrm{K}-\mathrm{K}$ & $45.50(6)$ \\
& & $\mathrm{O}(2)-\mathrm{K}-\mathrm{K}$ & $66.16(7)$ \\
& & $\mathrm{O}(1)-\mathrm{K}-\mathrm{K}$ & $131.89(7)$ \\
& & $\mathrm{K}-\mathrm{K}-\mathrm{K}$ & 180.0
\end{tabular}

This article is protected by copyright. All rights reserved. 


\section{Figure captions:}

Figure 1. XRD patterns; a) simulated pattern based on single crystal data of compound $\left[\mathrm{K}\left(\mu_{6}-\mathrm{HTA}\right)\right]_{\mathrm{n}} \quad(\mathbf{1}), \quad$ b) compound $\mathbf{1}$ nanostructures synthesized under ultrasonic irradiations, c) compound 1 after mechanochemical reaction with excess $\mathrm{TlNO}_{3}$, d) pure phase of $\left[\mathrm{Tl}\left(\mu_{3}-\mathrm{HTA}\right)\right]_{\mathrm{n}}(2)$, e) simulated pattern based on single crystal data of compound 2, f) compound $\mathbf{2}$ after mechanochemical reaction of it with excess $\mathrm{KNO}_{3}, \mathrm{~g}$ ) pure phase of 2 .

Figure 2. a ) A fragment of three-dimensional coordinat ion polymer in $\left[\mathrm{K}\left(\mu_{6}-\mathrm{HTA}\right)\right]_{\mathrm{n}}(\mathbf{1})$ wit h 1 ozenge fra mework along the crystallographic $\mathrm{c}$ axis and b) illustrating secondary st $\mathrm{raight} \mathrm{chain} \mathrm{K} \cdots \mathrm{K}$ interactions in 1 with purple dashed 1 ine along the crystallographic a axis, $(\mathrm{K}=$ purple, $\mathrm{O}=\mathrm{red}, \mathrm{C}=\mathrm{gr}$ ay and $\mathrm{H}=$ white, in part b $\mathrm{H}$ at oms have been o mit ted for clarit y).

Figure 3. SEM images of a) $\left[\mathrm{K}\left(\mu_{6}-\mathrm{HTA}\right)\right]_{\mathrm{n}}$ (1) nanostructures synthesized under ultrasonic irradiations, b) compound $\mathbf{1}$ after mechanochemical reaction with excess $\mathrm{TlNO}_{3}$, c) pure phase of $\left.\left[\mathrm{Tl}\left(\mu_{3}-\mathrm{HTA}\right)\right]_{\mathrm{n}}(\mathbf{2}), \mathrm{d}\right)$ compound 2 after mechanochemical reaction of it with excess $\mathrm{KNO}_{3}$, e) pure phase of 2 .

Figure 4. a ) A fragment of three-dimensional coordination polymer in [Tl $\left(\mu_{3}\right.$-HTA $\left.)\right]_{n}(2)$ wit h 1 ozenge fra mework al ong the crystallographic c axis and b) illustrating secondary straight chain Tl $\cdots \mathrm{Tl}$ interactions in 2 with purple dashed line along the crystallographic a a $\mathrm{x}$ is, $(\mathrm{Tl}=$ or a nge, $\mathrm{O}=\mathrm{red}, \mathrm{C}=\mathrm{gr}$ a y and $\mathrm{H}=$ whit e, in part b H at oms have been omit $t$ ed for clarit $y$ ).

Figure 5. Thermal behaviour of a) $\left[\mathrm{K}\left(\mu_{6}-\mathrm{HTA}\right)\right]_{\mathrm{n}}$ (1) nanostructures synthesized under ultrasonic irradiations, b) compound $\mathbf{1}$ after mechanochemical reaction with excess $\mathrm{TINO}_{3}$, c) pure phase of $\left[\mathrm{Tl}\left(\mu_{3}-\mathrm{HTA}\right)\right]_{\mathrm{n}}(\mathbf{2})$, d) compound 2 after mechanochemical reaction of it with excess $\mathrm{KNO}_{3}$, e) pure phase of 2 . 


\section{University Library}

\section{- M I I N E R VA \\ A gateway to Melbourne's research publications}

Minerva Access is the Institutional Repository of The University of Melbourne

\section{Author/s:}

Mirzadeh, E;Akhbari, K;White, J

Title:

Mechanochemical conversion of nano potassium hydrogen terephthalate to thallium analogue nanoblocks with strong hydrogen bonding and straight chain metalophillic interactions

Date:

2018-05-01

Citation:

Mirzadeh, E., Akhbari, K. \& White, J. (2018). Mechanochemical conversion of nano potassium hydrogen terephthalate to thallium analogue nanoblocks with strong hydrogen bonding and straight chain metalophillic interactions. APPLIED ORGANOMETALLIC CHEMISTRY, 32 (5), https://doi.org/10.1002/aoc.4313.

Persistent Link:

http://hdl.handle.net/11343/283914 